\title{
Novas e antigas diásporas: a comunicação transcultural entre senegaleses e árabe- brasileiros no sul do Brasil
}

\section{Guilherme Oliveira Curi}

Universidade Federal de Santa Maria, Programa de Pós-Graduação em Comunicação, Santa Maria, RS, Brasil

ORCID: https://orcid.org/0000-0002-9464-4231

\section{Liliane Dutra Brignol}

Universidade Federal de Santa Maria, Programa de Pós-Graduação em Comunicação, Santa Maria, RS, Brasil

ORCID: https://orcid.org/0000-0002-7323-038X

\section{Resumo}

O artigo traz reflexões a partir de um estudo comunicacional sobre as relações socioculturais e religiosas, entre a recente imigração senegalesa na região sul do Rio Grande do Sul, iniciada na segunda década de 2000, e os árabe-brasileiros, descendentes de palestinos, que vivem no Brasil desde o começo do século passado. A base teórica para este estudo está fundamentada a partir dos pressupostos de Muniz Sodré, Stuart Hall e Jacques Rancière. Foi realizada uma pesquisa de campo com observação simples e entrevistas semiestruturadas com representantes de ambas as comunidades. Observamos que as interações comunicacionais se demonstraram possíveis e ativas entre as comunidades, com aspectos de colaboração, compreensão, assim como desentendimentos e diferentes apropriações de usos e práticas midiáticas.

\section{Palavras-chave}

Migrações. Cultura Contemporânea. Religião. Novas Tecnologias. Diáspora. 


\section{Introdução}

Em um mundo midiatizado, aparentemente global e plural, mas regido por uma ideologia neoliberal e capitalista hegemônica, caracterizado por desigualdades sociais abissais e crises sistêmicas que impulsionam e aceleram os deslocamentos humano, são produzidos encontros socioculturais que, ao primeiro olhar, parecem inusitados e singulares. No entanto, tais encontros, por mais que pareçam pequenas interações sociais, não acontecem por obra do acaso e muito têm a dizer para o campo comunicacional contemporâneo.

Este artigo, fruto do resultado de uma pesquisa de pós-doutorado no Programa de Pós-Graduação em Comunicação na Universidade Federal de Santa Maria (POSCOM UFSM), finalizado no ano de 2020, busca analisar as relações socioculturais, na cidade de Rio Grande - RS, entre a recente imigração senegalesa, iniciada na segunda década de 2000, e a comunidade dos árabe-brasileiros, de origem palestina, que vivem no Brasil desde o começo do século passado. 0 que liga ambas as comunidades são as práticas religiosas do Islã. Assim como muitos árabe-brasileiros que aqui residem há quase um século, a grande maioria dos senegaleses que chega ao Brasil é muçulmano. Logo, o local de encontro entre as diferentes culturas ocorre nas mesquitas.

De acordo com Martino (2016), a relação entre mídia e religião na sociedade contemporânea ganha novas dimensões. Promovida pelos ambientes digitais, a lógica da mídia e as práticas da religião acabam permeando áreas como cultura, economia e política entre outros aspectos da vida em sociedade. Embora pareça muitas vezes uma questão de fé individual, a religião, vivida em público, torna-se uma prática social, um importante tema para a Comunicação, pois a maneira "como a pessoa religiosa se veste, fala, vive com os outros, escolhe seus relacionamentos afetivos ou mesmo profissionais está, em alguma medida, ligado às suas crenças" (MARTINO, 2016, p. 9).

Deste modo, a cidade onde as práticas religiosas acontecem, é percebida como o imperativo estrutural de tornar comum as diferenças ou de unir os opostos que, em sua dinâmica, torna-se palco das mediações socioculturais tão determinantes no campo comunicacional (SODRÉ, 2014). Rio Grande, principal campo da pesquisa, possui cerca de 207 mil habitantes e está localizada no extremo sul do país, entre a Lagoa Mirim, a Lagoa do Patos e o Oceano Atlântico. É um dos portos mais antigos do Brasil, primeira capital do Rio Grande do Sul, com uma história populacional marcada pelo fluxo de 
diferentes comunidades étnicas nos últimos séculos, entre eles: europeus, africanos, árabes e asiáticos.

\section{Metodologia e perspectivas teóricas}

De acordo com o relatório da Organização Internacional para Migrações (2020), cerca de 24 milhões de pessoas vivem em outros países diferente dos seus, o que representa 3,3\% da população mundial (Word Migration Report, 2020). Ainda, segundo dados da Polícia Federal, apenas no ano passado, 179 mil estrangeiros pediram a regularização no Brasil, dos quais 5.564 são do continente africano - alguns deles com pedido de refúgio (Cavalcanti et al., 2019).

Logo, a reorganização nas tendências e características dos fenômenos migratórios exige uma reavaliação dos paradigmas para a compreensão e análise das migrações transnacionais na medida em que novas modalidades de deslocamentos humanos não são mais caracterizadas apenas por sua expressão numérica, mas marcadas por uma rede complexa de significados, decorrentes de diferentes diásporas. 0 fenômeno migratório é assim caracterizado, de acordo com ElHajji (2012), por "laços de sentido que se tecem e se densificam, costurando a teia simbólica global que vem cobrindo o mundo e reformulando a sua morfologia social e humana - discursiva, imaginaria e biológica" (ELHAJJI, 2012, p. 34). Dentro desta teia simbólica global está a comunicação, arena fundamental onde se negocia o status social, cultural e político das migrações.

Para Sodré (2014), a comunicação revela-se como principal forma organizativa na sociedade contemporânea. Revelar-se, segundo o autor, porque comunicação significa, de fato, em sua radicalidade, "o fazer organizativo das mediações imprescindíveis ao comum humano, a resolução aproximativa das diferenças pertinentes em formas simbólicas" (SODRÉ, 2014, p. 15). Ou seja, interação subjetiva, colocar-se em comum, concatenar-se, onde a vinculação humana é o problema central da comunicação. Tal concepção é influenciada pelo pensamento de Jacques Rancière, que observa o vínculo indissolúvel entre comunicação, religião e política, no modo como as operações do fazer são partilhadas pelos membros dentro de uma comunidade. Para o autor, a política habita o campo dos afetos, possui sempre uma dimensão estética, vinculativa, comunicativa. Ainda, o autor sustenta que a política existe apenas como subjetivação de uma parte dos "sem parte", que reativa a "contingência da igualdade, nem aritmética nem geométrica, entre os seres dotados de 
linguagem", o que, por sua vez, perturba "a narrativa das partes, a arquitetura distributiva" (RANCIÈRE, 2018, p. 28), os excluídos.

Isto posto, a partir destes primeiros pressupostos teóricos, no âmbito empírico, foi realizada uma pesquisa de campo com observação simples, registros fotográficos, que auxiliam na percepção do tema para além das palavras, e seis entrevistas semiestruturadas com os imigrantes senegaleses e árabe-brasileiros, além da investigação crítica das práticas comunicacionais e religiosas. A escolha por entrevistas semiestruturadas, com perguntas fechadas e abertas, deu-se pelo fato de proporcionar ao entrevistado a possibilidade de discorrer sobre diferentes temas e servir como base para a análise sociocultural proposta.

Os questionamentos basilares que compuseram o roteiro principal, com pequenas diferenças entre as perguntas para cada integrante de respectiva comunidade, foram: Quanto tempo o imigrante está no Brasil, no caso dos senegaleses, e qual o tempo que a família do árabe-brasileiro vive no Brasil; profissão, se graduado ou algum curso técnico; estado civil; idade; o motivo de ter imigrado para o Brasil; diferentes tipos de rituais e práticas religiosas; possíveis dificuldades das práticas religiosas na sociedade brasileira; e, por fim, sobre as diferenças culturais entre os brasileiros, senegaleses e descendentes de árabes.

A pesquisa caracteriza-se também a partir de uma perspectiva metodológica transcultural, que, de acordo com Sodré (2017), seria diferente de sobreposições multiculturalistas, em que a afeição pelo pensamento exótico admite harmonizações, mas sempre sob o escudo da lógica hegemônica. Segundo o autor, é um desafio que induz à prática de uma dialogia semiótica, em outras palavras, diferente de um diálogo entre formações que "ambicionem ser verdadeiras, inertes e estanques, mas sim uma lógica do trans ou do vaivém através dos limiares do sentido [...] que não são necessariamente conciliatórias ou harmônicas, mas que abrem caminhos para novos termos das disputas de sentido" (SODRÉ, 2017, p.22).

De maneira semelhante, Hall (2003) sugere observar a cultura como o campo das práticas, linguagens, representações costumes concretos de qualquer sociedade historicamente específica. Para o autor, no processo de significação da cultura é necessário analisá-la como mapas conceituais compartilhados e sistemas de linguagem compartilhada por meio de códigos que conduzem as relações de tradução, entre eles, neste caso, as práticas comunicacionais e religiosas analisadas. Ou seja, nas próprias palavras do autor, "o sentido não é inerente às coisas, ao mundo. Ele é construído, produzido [...] é o resultado de uma prática significante - uma prática que produz sentido" (HALL, 2016, p. 38). 
Em um argumento teórico análogo, Gilroy (2001) afirma que as culturas na diáspora são produzidas por meio de ciclos de chamada e resposta na qual podem ser perdidas, encontradas e novamente renovadas. Segundo o autor, tais fenômenos nos desafiam a compreender a cultura como algo mutável e itinerante, algo que gera uma potência complexa de dinâmicas de memórias vivas. Portanto, essa dispersão de pessoas ao redor do mundo produz culturas que são moldadas e localizadas em diferentes lugares simultaneamente, como veremos a seguir, por meio da pesquisa de campo proposta.

Por conseguinte, no começo do terceiro milênio, estudos sobre diferentes diásporas proporcionaram o desenvolvimento de um escopo de pesquisas voltado para as relações das comunidades migrantes por meio das Tecnologias da Informação e Comunicação (TICs), o que resultou no conceito de 'webdiáspora' enquanto "espaço de reordenamento das experiências e práticas subjetivas dos imigrantes transnacionais" (ELHAJJI \& ESCUDERO, 2015, p. 13). Ou seja, em termos práticos, podemos definir a webdiáspora a partir da reapropriação das TICs pelos imigrantes e os usos sociais e subjetivos delas decorrentes. Ao recorrer à webdiáspora, a comunidade migrante "consegue tecer e reforçar suas redes sociais, econômicas, políticas e culturais transnacionais, sem, todavia, deixar de edificar um espaço simbólico que reproduz ou simula o estar-junto na 'pátria' de origem" (ELHAJJI \& ESCUDERO, 2015, p. 14).

Logo, a partir de uma dimensão interacional ampla, buscamos compreender as questões vinculativas entre a comunidade árabe-brasileira muçulmana e os novos imigrantes senegaleses. 0 que as práticas comunicacionais destas novas e antigas diásporas têm a nos dizer? Para além do vínculo religioso, de que formas estas comunidades interagem? Há uma colaboração mútua no sentido de desenvolver ações efetivas e organizações para compor dinâmicas de mobilização relacionadas à cidadania política destes imigrantes?

No intuito de responder a estas questões, no próximo tópico atentaremos para a trajetória de ambas as comunidades e principais características de associativismo cultural e religioso em situação de diáspora. Além disso, também será realizada uma breve análise descritiva do desenvolvimento dos processos migratórios e suas relações com as novas mídias. Na parte final, iremos descrever a pesquisa de campo que foi realizada em Rio Grande além de relatar e analisar as questões que surgiram a partir das entrevistas com os integrantes de ambas as comunidades. Por questões éticas, não utilizaremos os nomes dos entrevistados. 


\section{A imigração senegalesa no Brasil}

A diáspora senegalesa espalhou-se por diferentes continentes no último século. Os locais mais antigos de fluxos migratórios são Europa e vários países da África Ocidental, já na América do Norte e na do Sul a imigração senegalesa é mais recente. Assim como lembra Tedesco (2019), os senegaleses chamam a atenção nos locais de destino por suas manifestações religiosas, linguísticas, culturais e associativismo. Além disso, a prática do comércio informal, nas regiões centrais das cidades, assim como também acontece em Rio Grande, tem "provocado conflitos e embates e ao mesmo tempo revelado dinamismosinventividades e estratégias mercantis" (TEDESCO, 2019, p. 2).

Apesar do país localizado na costa oeste africana não ter guerras internas, como outros países do continente, o Senegal sofre de sérios problemas de desigualdade social, o que motiva muitos a migrarem. A falta de emprego pode ser identificada como um dos fatores estruturais mais importantes no contexto do país de nascimento. "Senegal é bom, mas falta trabalho" é uma frase constante presente nas falas dos imigrantes pesquisados.

A imigração senegalesa no Brasil é recente e começa a partir da segunda década de 2000. De acordo com dados da Secretaria Nacional de Justiça (2018), 7.206 solicitações de refúgio foram feitas por senegaleses entre os anos de 2010 e 2015. Ao passar na fronteira, a maioria faz o pedido de refúgio, o que garante a possibilidade fica regular no Brasil, previsto por lei, e ter carteira de trabalho. No entanto, após o período estipulado, alguns senegaleses têm seus pedidos negados, o que resulta em muitas dificuldades sociais. A imigração senegalesa no Brasil é caraterizada por ser masculina, na faixa etária entre 19 e 50 anos (JUNG, 2019, p. 58).

Ainda, para Jung (2019) e Tedesco (2019), podemos dividir a emigração recente do país do Senegal para o Brasil em três períodos. A primeira acontece até meados de 2012, quando não mais de mil senegaleses estiveram em território nacional e que, para vários deles, o Brasil foi mais uma etapa na trajetória migratória antes de migrar para outros países. A segunda, a partir de 2013 e até o fim de 2015, período de maior fluxo, quando os senegaleses entram no Brasil, via Equador, que permitia que os imigrantes entrassem na América Latina sem qualquer regulamento de visto. Já a terceira fase, a atual, é caracterizada pela crise econômica e política brasileira, que resultou na saída de considerável número de senegaleses do país.

Isto posto, por meio das entrevistas realizadas com os imigrantes senegaleses podemos perceber estas mudanças mencionadas. 0 entrevistado 1 mora há 7 anos no Brasil, 
na cidade de Rio Grande - RS. Após ter a carteira assinada, atualmente trabalha no comércio de rua local. É casado e tem dois filhos. No trecho seguinte, é possível destacar as razões de migrar do Senegal para sul do país.

\begin{abstract}
O Senegal não é um país muito pobre, mas que não é tão bom também. Eu sou formado, fiz universidade, tenho diplomas, eu era professor de francês e árabe, falo cinco idiomas, mas não conseguia fazer dinheiro suficiente para sustentar minha família. Esse é o motivo de todos os senegaleses estarem aqui. Nos saímos para tentar uma vida melhor e fizemos contatos com as pessoas que já saíram. O Brasil é um dos países com as portas mais abertas, já tentei ir pra França, Itália e Espanha, mas sempre foi bem difícil de conseguir visto ou entrar clandestinamente nessas cidades, mesmo arriscando a vida. Mas, em 2013, o Brasil era visto como uma oportunidade para os senegaleses, teve um projeto dos haitianos que estavam entrando por Rio Branco, e os senegaleses se juntaram para poder entrar no Brasil, pra buscar uma vida melhor [...] A vida está bem difícil lá, não temos guerra, problemas graves, mas tá bem difícil. (ENTREVISTADO 1).
\end{abstract}

De fato, o imigrante entrevistado é um entre milhares de senegaleses que vivem hoje no Rio Grande do Sul. Infelizmente, não existem dados concretos e oficiais no Estado, pois alguns permaneceram indocumentados após terem o pedido de refúgio negado. No entanto, segundo organizações não governamentais e associações dos próprios imigrantes, calculava-se que cerca de 3,9 mil senegaleses estavam residindo no Rio Grande do Sul até o começo de 2019, em torno de dois mil estariam na capital, Porto Alegre. Já de acordo com o líder da Associação dos Senegaleses de Rio Grande - RS, cerca de 150 imigrantes senegaleses vivem hoje na cidade. A outra grande parte está na Serra Gaúcha, principalmente na cidade de Caxias do Sul e adjacências. A tendência, como veremos a seguir, é que parte destes imigrantes esteja deixando o Estado.

No entanto, para compreendermos a complexa diáspora senegalesa além das questões sociais e econômicas é necessário analisarmos as práticas religiosas e a inserção coletiva destes imigrantes. Atualmente, mais de $90 \%$ da população do Senegal é de orientação mulçumana. Entre as várias vertentes de seguidores do Islamismo estão os sufis, de caráter místico, como o Mouridismo, uma das confrarias mais representativas no contexto da diáspora senegalesa. De acordo com Lacomba (2001), um dos primeiros pesquisadores a investigar a prática islâmica dos senegaleses na nova diáspora, as formas de estruturação e organização das confrarias entre os muçulmanos senegaleses na diáspora demostram o potencial do mouridismo no contexto de imigração.

As confrarias muçulmanas pertencem ao "universo de manifestações místicas coletivas do islão e são, de forma estruturada, a mais antiga e importante expressão da 
espiritualidade muçulmana, o sufismo" (DIAS, 2007, p. 2). Há alguns séculos as confrarias sufis no Senegal desempenham papel fundamental na expansão do Islã. Desde finais do século XIX, os dirigentes destas confrarias tornaram-se os principais interlocutores entre os muçulmanos e o Estado, os chamados marabus, ou marabouts, que segundo Sambe "são hoje, como no passado colonial, uma referência essencial no jogo político senegalês" (SAMBE, 2007, p. 2).

Outro elemento de destaque são as dahiras, que significa círculo, ou seja, uma associação local de membros da confraria mouride. De acordo com Heil (2008), ela representa uma forma organizativa onipresente no mundo dos senegaleses, "um lugar de encontro, de oração e recitação dos poemas [...] mas também de prestação de apoio mútuo, de troca de informações e até de interações comerciais (HEIL, 2018, p. 113).

Além disso, um dos mais importantes elementos para compreensão da cultura senegalesa na diáspora é o significado simbólico e vinculativo do Cheikh Ahmadou Bamba, fundador do mouridismo no século XIX. De acordo com Rossa, o sistema que Bamba projetou era baseado em uma educação voltada para transformar o caráter e o comportamento de seus discípulos. No entanto, a reputação de Bamba atraia muitos discípulos e, com o passar dos anos, chamou a atenção do poder colonial francês, que não compactuava "com o proselitismo da confraria e a atitude pouco cooperante do seu líder com a administração da época" (ROSSA, 2019, p. 296) Com isso, o poder colonial francês o acusou de subversão e o obrigou a deixar o país por duas vezes. Assim, as provações pelas quais Bamba enfrentou fizeram com que aumentasse ainda mais a sua admiração. Logo, uma das heranças religiosas mais importantes deixadas aos mourides é o Grand Magal de Touba. A celebração seria "um pedido feito pelo próprio Cheikh Ahmadou Bamba aos seus discípulos, em comemoração ao aniversário de sua primeira partida para o exílio no Gabão" (ROSSA, 2019, p. 297). Assim, o Magal de Touba, comemorado no dia 18 do mês de Safar do calendário muçulmano, transformou-se em um importante feriado religioso quando milhões de seguidores visitam a cidade de Touba, transmitido em tempo real por meio das mídias digitais.

A celebração é realizada por comunidades senegalesas em diversas cidades ao redor do mundo. Logo, é de suma importância destacar os usos e as apropriações das novas tecnologias móveis e a transmissão ao vivo do Magal, assim como a circulação de imagens nos quatro cantos do mundo as quais "aludem aos sentidos de co-presença e de mobilidade, evidenciando o caráter transnacional do próprio Mouridismo e de suas ressignificações a partir do passado colonial do Senegal e em sua dimensão diaspórica" (BRIGNOL \& COSTA, 
2018, p. 25). Por meio das transmissões da festa do Grand Magal, é reforçada a memória do exílio do sheik e o papel da religião como resistência diante do domínio francês, enquanto, concomitantemente, atualiza-se a cerimônia como marca da presença migrante no Brasil e em outros países. O Magal configura-se assim como um evento transnacional pelo sentido comunicativo, de partilha. As mesmas práticas, costumes e recitais são realizadas em diferentes cidades, no mesmo dia, com o compartilhamento de informações e de fotografias, com os usos da internet.

\section{A imigração árabe-mulçumana no Brasil}

A história da diáspora árabe confunde-se com a própria história do mundo. Desde o longínquo surgimento do Islã, por meio da conquista de novos califados, passando pela chegada dos árabes ao continente europeu na Península Ibérica e na África, ambos na Idade Média, até a expansão do Império Turco-Otomano na Idade Moderna, a diáspora árabe islâmica espalhou-se por todo o mundo, misturando-se a outras práticas socioculturais e representações simbólicas, assim como observamos no Senegal, por meio do mouridismo.

Já a diáspora árabe moderna para as Américas tem sua primeira grande leva migratória iniciada a partir do final do século XIX, composta, em sua maioria, por cristãos da então chamada região do Levante. Os momentos de maior imigração árabe aconteceram entre 1904 e 1914, no período das tensões anteriores à Primeira Guerra Mundial, "com um pico de 10.886 imigrantes em 1913" (PINTO, 2010, p. 50). Após a interrupção causada pela guerra, o fluxo migratório ganhou novamente intensidade entre 1920 e 1926, período de instabilidade no Oriente Médio devido à instalação do mandato francês sobre a Síria e o Líbano. Em seguida, ao longo da década 1930, após a adoção de um sistema de cotas de imigração para cada nacionalidade, a imigração árabe declinou, para somente voltar a crescer nos anos de 1950, devido à ocupação ilegal israelense em terras palestinas e a criação do Estado de Israel, em 1948, motivo principal que resultou na vinda da primeira geração de palestinos para o sul do Brasil, país daqueles que fundaram a mesquita em Rio Grande - RS, como veremos.

Nas décadas seguintes, os constantes conflitos bélicos, como a Guerra dos Seis Dias ${ }^{1}$, de 1967, fizeram com que milhares de palestinos migrassem. É necessário ressaltar aqui o

\footnotetext{
${ }^{1}$ Conflito militar que teve início em 5 de junho de 1967, quando as forças armadas de Israel objetivaram neutralizar a futura ofensiva dos países vizinhos. Foi um ato bélico preventivo do Estado de Israel que derrotou as forças armadas egípcias, jordanianas e sírias. No dia 10 de junho, a guerra estava terminada com Israel na posse da Faixa de Gaza, Península do Sinai e das colinas de Golã
} 
significado que o estado israelense tem para os árabes mulçumanos, principalmente quando o movimento sionista judaico ganha força na segunda metade do século XX, com o apoio de nações ocidentais. No entanto, destacamos que objetivo deste artigo não é detalhar os meandros do conflito, que até hoje trazem à tona diversas formas de violência no Oriente Médio e que refletem na organização das comunidades palestinas na diáspora.

Isto posto, assim como para os senegaleses, a religião islâmica também é suma importância para a compreensão da migração árabe no Brasil. Os imigrantes árabesmulçumanos somente começaram a criar suas instituições religiosas a partir dos anos de 1930. Além das dificuldades compartilhadas pelos outros grupos religiosos, esse atraso de institucionalização pode ter influenciado devido a vontade de manter uma baixa visibilidade, ou seja, "não suscitar a mobilização das representações estigmatizantes do islã que circulavam na sociedade brasileira" (PINTO, 2010, p. 115). Segundo Montenegro (2013), a adesão a um islã desconectado da questão árabe ocorre até hoje, assim identificado pela pesquisadora, na Sociedade Beneficente Mulçumana do Rio de Janeiro, fundada em 1950 por imigrantes que se reconheciam como árabes-mulçumanos. Segundo a antropóloga, "descendentes daquele pequeno grupo inicial contam que houve uma época em que se podia ver nas paredes da Sociedade retratos daqueles líderes internacionais que pugnavam pela unidade árabe" (MONTENEGRO, 2013, p. 41). No entanto, hoje já não se encontram mais vestígios dessas alusões. 0 que a pesquisadora notou foi justamente o esforço entre os dirigentes da instituição para "des-etnificar o Islã, separando-o de qualquer associação como o componente árabe" (MONTENEGRO, 2013, p. 42).

\section{0 encontro entre as diferentes diásporas}

O trabalho de investigação de campo teve início no final do ano de 2018, quando participamos do Primeiro Festival de Arte e Cultura Senegalesa, realizado entre os dias 13 e 14 de outubro, no Memorial do Rio Grande do Sul, em Porto Alegre. 0 evento foi organizado pela Associação dos Senegaleses de Porto Alegre e contou com o apoio de entidades nãogovernamentais, sindicatos e do diretório central dos estudantes da Universidade Federal do Rio Grande do Sul (DCE/UFGRS). Na ocasião, foram realizadas conversas e observação das atividades, como apresentações musicais, danças, exposição de pinturas, palestras, exibição de filmes, culinária e mostra da luta tradicional $L a a m b^{2}$. Segundo a organização, em

\footnotetext{
2 Considerado um esporte tradicional e popular no Senegal e na Gâmbia. É uma luta em que o praticante pode socar o adversário, bem como recorrer ao combate corpo a corpo. Inicialmente um esporte amador, a luta senegalesa se tornou um esporte profissional.
} 
torno de 300 pessoas participaram do festival, que foi transmitido pelas próprias mídias dos imigrantes senegaleses, como fotos e posts na página do Facebook da associação, que está em plena atividade, além, da cobertura de veículos de mídia local e estadual.

Não é o intuito deste artigo descrever detalhadamente o festival, mas sim ressaltarmos a importância do encontro para compreendermos, em um primeiro momento, as relações dos senegaleses com as comunidades locais em um sentido comparativo com as comunidades do município de Rio Grande. Neste encontro, não percebemos um vínculo direto com a comunidade árabe-brasileira de Porto Alegre, mas uma intensa relação dos líderes da comunidade senegalesas com os movimentos afro-gaúchos, de luta pelos direitos dos povos de cultura afro-brasileira. A consciência política com relação ao tema presente nas falas, nos debates e nas produções midiáticas próprias, principalmente no encerramento do evento, foi algo marcante. Tal fator pode ser compreendido também pelo momento em que o festival foi realizado. 0 Brasil estava em um período de eleições estaduais e presidenciais, prestes a ser governado por um presidente de extrema-direita, que afirma publicamente ser avesso às causas das comunidades quilombolas e povos de origem africana.

Já na cidade de Rio Grande, localizada 318 quilômetros ao sul de Porto Alegre, local onde se concentrou a pesquisa, iniciamos nosso trabalho de campo no começo de 2019, quando entrevistamos representantes de ambas as comunidades e participamos dos cultos religiosos na mesquita. De acordo com o presidente da Associação dos Senegaleses de Rio Grande (ENTREVISTADO 2), os primeiros imigrantes chegaram em 2013 à cidade.

\footnotetext{
Eu cheguei com mais nove pessoas, no mesmo dia conseguimos dez vagas de serviço, um mês depois chegaram mais pessoas e conseguiram emprego. Estava fácil de conseguir trabalho com carteira assinada. Trabalhei por três anos na fábrica de peixes Torquato Pontes. Alguém chegava e era empregado. Estamos aqui pra trabalhar, ganhar dinheiro, quem tem carteira assinada vai nos dar a mão. Mas, com o tempo, a gente percebeu que estava mudando a situação, os senegaleses foram demitidos e, por isso, começamos a vender, mesmo sabendo que não era legal. Já tivemos mais de 250 senegaleses aqui, muitos já foram embora. Agora somos uns 150 , menos da metade tem carteira assinada, uns 70 , diria. A situação mudou, está bem difícil. Se está difícil para os brasileiros, imagina pra nós. (ENTREVISTADO 2).
}

O relato retrata aquilo que Jung (2019) descreve como as três mudanças de fases da imigração senegalesa no Brasil nos últimos anos. Vale ressaltar que Rio Grande foi uma das cidades mais afetadas pela crise econômica e política brasileira. No começo da segunda 
década de 2000, o projeto do Governo Federal de construção de plataformas de petróleo da Petrobrás no estaleiro do Porto Novo de Rio Grande gerava mais de 30 mil empregos diretos e indiretos, o que fez com que a economia da cidade crescesse vertiginosamente. 0 quase total declínio da indústria naval em meados de 2016, muitas demissões e o fechamento de comércios locais logo após o impeachment da presidente Dilma Rousseff, gerou uma drástica crise econômica e social na cidade. Somente a empresa Engevix Construções Oceânicas, umas das empreiteiras contratadas para as obras do Polo Naval, segundo notícia vinculada no site da Prefeitura Municipal de Rio Grande (2016), demitiu 3,2 mil funcionários de uma só vez. Ainda, de acordo com dados da prefeitura da cidade, em 2017 o município deixou de arrecadar cerda de $\mathrm{R} \$ 70$ milhões em impostos.

No entanto, mesmo com a crise, muitos senegaleses permaneceram no município. Apontamos aqui algumas hipóteses para estes imigrantes continuarem na cidade. A primeira é a flexibilidade para a prática do comércio informal, apesar das dificuldades impostas pelos comerciantes locais e pelo poder público. De acordo com alguns dos entrevistados, a maioria dos fiscais da prefeitura municipal não confisca os produtos comercializados. Outras hipóteses podem ser enumeradas: durante o verão, Rio Grande, cidade costeira, atrai cerca de 150 mil turistas para a praia, o que faz com que os migrantes senegaleses possam também comercializar mercadorias na orla marítima; além disso, alguns senegaleses apontaram não haver tantos casos de racismo comparado a outras cidades gaúchas. Tal fato dá-se, talvez, por Rio Grande ter uma maior miscigenação de culturas devido ao porto marítimo e ao fluxo constante e histórico de imigrantes na cidade, como africanos e os árabe-brasileiros que residem no município, ponto chave para esta investigação.

Em Pelotas, por exemplo, munícipio vizinho, em recente pesquisa etnográfica junto à comunidade senegalesa que vivia na cidade entre os anos de 2015 e 2016, as pesquisadoras Simone Roberto e Patrícia Pinheiro apontam que os imigrantes senegaleses foram duramente reprimidos no exercício das suas atividades comerciais. Em determinadas ocasiões, relatam que "a repressão instituída pela Guarda Municipal implicou em um forte uso de aparato armado, como: gás de pimenta, armas de choque e ameaças à mão armada" (ROBERTO \& PINHEIRO, 2019, p. 130).

O seguinte relato de um dos senegaleses entrevistados, homem, 29 anos, há quatro vivendo em Rio Grande, nos dá indícios da confirmação destas hipóteses: 
Em Rio Grande, há mais compreensão, não há barbárie. Mas em outras cidades estão mais rigorosos, com mais agressões, é mais violento. Fiquei com raiva na minha primeira vez que vi e passei por isso em Pelotas. As pessoas de Rio Grande são mais flexíveis e simpáticas. Nessas cidades que nos tratam mal, a maioria já saiu. (ENTREVISTADO 3).

Ainda, entre os meses de janeiro e setembro de 2019, passamos a acompanhar em diferentes sextas-feiras, na primeira hora da tarde, os cultos na mesquita localizada no centro da cidade, além de participar de algumas reuniões religiosas de ambas as comunidades.

De acordo com um dos líderes da comunidade palestina (ENTREVISTADO 4), homem, 54 anos, casado, filho de palestinos, o grupo que se reúne na mesquita faz parte da Sociedade Beneficente Islâmica Árabe Palestina Brasileira e foi criado há cerca de 18 anos a partir de encontros e resoluções que aconteceram durante o Fórum Social Mundial, em Porto Alegre, no ano de 2001. O Fórum foi um evento organizado por movimentos sociais globalmente com objetivo de elaborar e construir alternativas, com o slogan: "Um outro mundo é possível". Aqui, é importante salientar que a causa da libertação da Palestina é uma das pautas de movimentos sociais e políticos progressistas presentes no encontro, instrumento ideológico pertinente na comunidade árabe local. Uma bandeira do Estado Palestino, por exemplo, está hasteada na entrada da mesquita ao lado bandeira brasileira, fato oposto ao constado por Montenegro (2013), contextualizado anteriormente, ao afirmar que na mesquita carioca há uma "des-etnificação do islã" e desconexão com as causas árabes.

A atual mesquita, localizada em uma casa na Rua Carlos Gomes, centro da cidade, existe desde 2017. Antes era localizada em outro local, onde a comunidade permaneceu por 15 anos. Os árabe-brasileiros mulçumanos que a frequentam são de orientação sunita, assim como a grande maioria dos muçulmanos, que somam cerca de $85 \%$ no mundo. Ao todo, na comunidade, somam-se cerca de 20 pessoas praticantes, todos homens, entre $25 \mathrm{e}$ 65 anos, a maioria oriundo de famílias palestinas que migraram para Rio Grande há quase 60 anos. Há também dois brasileiros convertidos ao Islã.

$\mathrm{Na}$ maioria das vezes que estivemos na mesquita, foi constatado que os árabebrasileiros eram os primeiros a chegar. Aos poucos, os senegaleses chegam ao recinto e logo se tornam maioria numérica. Dentro da mesquita, todos falam em árabe, ainda que os sermões sejam realizados em árabe e português. A mesma frase é lida duas vezes, em ambas as línguas. Certa vez, um dos integrantes da comunidade palestina reclamou em árabe com um senegalês que ele estava atrasado. Algo que nos chamou a atenção. 0 árabe, mesmo não 
sendo a língua oficial de ambos os países, naquele local se torna a língua principal, um instrumento central de vinculação, supranacional e transcultural.

Constatou-se também que, em alguns momentos, os imigrantes senegaleses registram os cultos religiosos via smart phones, assim como acontece no Grand Magal e no festival de Porto Alegre, algo mais presente entre eles do que entre os árabe-brasileiros. $\mathrm{Na}$ mesquita, os senegaleses enviam, por meio dos celulares, imagens para o Senegal e a outros países, em tempo real. Uma forma de manter vínculos com a terra natal, com a circulação de imagens ao redor do mundo, que aludem aos sentidos de mútua presença e mobilidade, evidenciando, mais uma vez, o caráter transnacional do Mouridismo e de suas ressignificações. A mediação tecnológica na experiência religiosa de migrantes senegaleses não somente traz implicações para os sentidos das múltiplas temporalidades migrantes, mas torna-se constitutiva da própria migração, ou seja, torna-se parte do fazer organizativo ao comum humano.

Ainda, em uma das entrevistas, um dos imigrantes senegaleses contou que, em todas as sextas-feiras, ao ir à mesquita, sentia-se mais próximo do seu país: "Quando venho aqui é como eu estivesse indo ao Senegal" (ENTREVISTADO 3). De fato, muitos destes imigrantes senegaleses, assim com o entrevistado, trocam suas roupas casuais de trabalho por roupas tradicionais islâmicas momentos antes de adentrarem a mesquita, algo muito simbólico, interpretado por nós como uma espécie de eterno retorno à própria casa. Aqui, Sayad (1998) nos auxilia na reflexão ao apontar que estado de migração nunca termina, é condição permanente, composta pela dualidade da presença. Ou seja, ao ocupar um novo lugar, o imigrante/emigrante deixará outro vazio e se tornará, “atopo, sem lugar, deslocado, inclassificável [...] nem cidadão, nem estrangeiro, nem totalmente do lado do mesmo, nem totalmente do lado do outro" (SAYAD, 1998, p. 11). 
Figura 1 - Registro de um momento de oração na mesquita de Rio Grande.

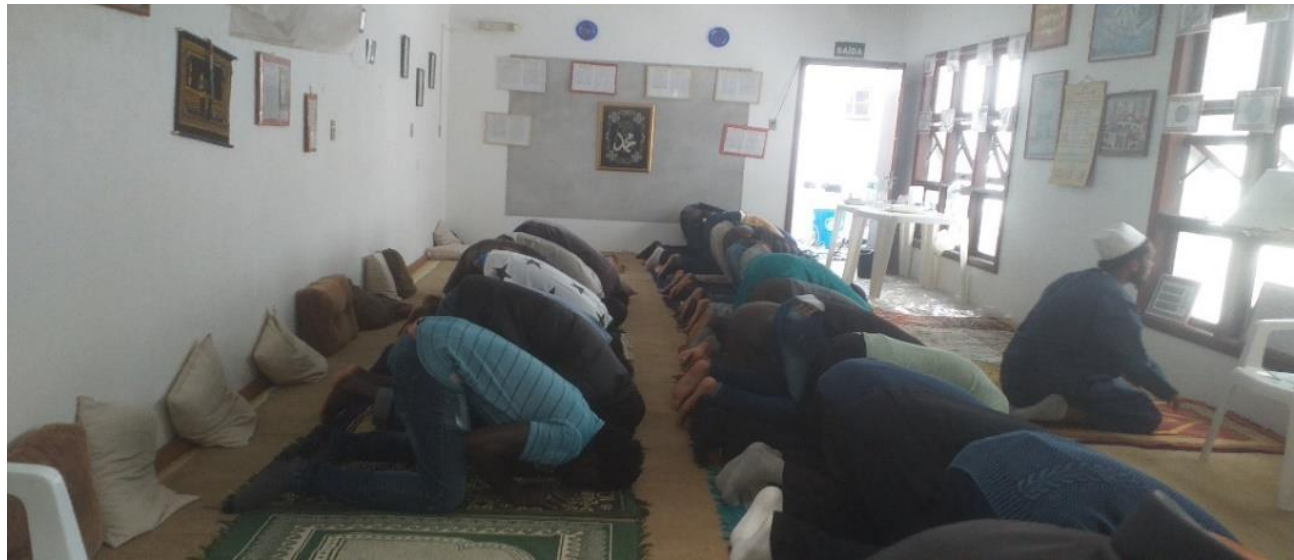

Fonte: Arquivo pessoal.

A mesquita fica localizada ao lado da Praça Tamandaré, local onde os senegaleses vendem seus produtos. A foto a seguir foi feita uma hora antes do imigrante trocar de roupa e caminhar até o local de oração próximo ao seu trabalho.

Figura 2 - Imigrante senegalês no centro de Rio Grande - RS.

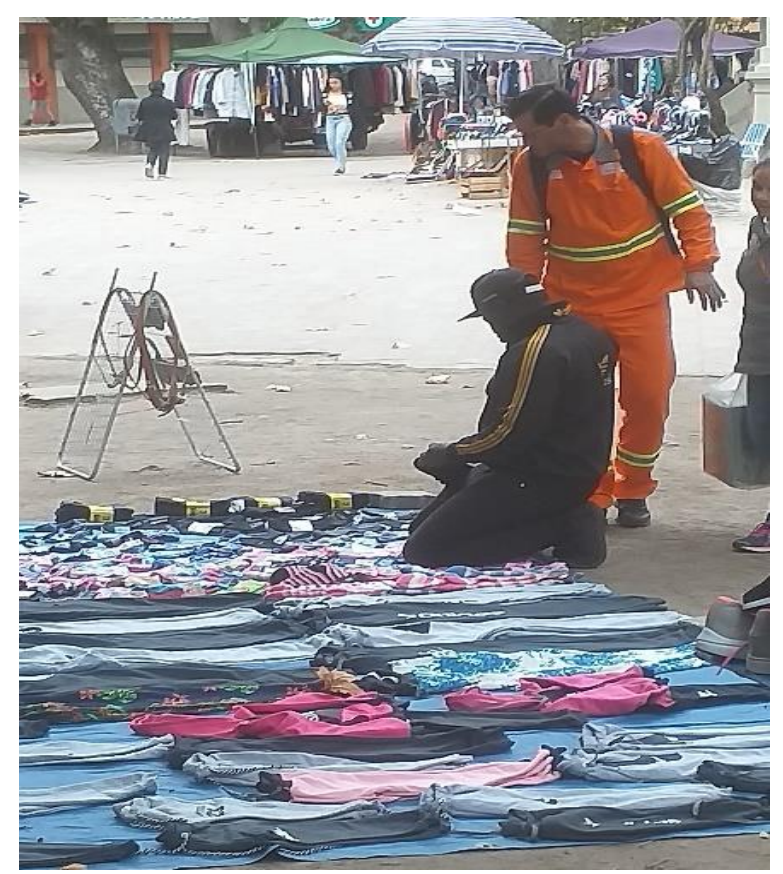

Fonte: Arquivo pessoal.

Destarte, a Associação Senegalesa de Rio Grande mantém uma página no Facebook na tentativa de manter o laço virtual e também de diálogo com a comunidade local, algo presente no fenômeno da webdiáspora, que remete a um espaço virtual de migrantes, criado ou gerenciado por migrantes ou em parceria com eles. 0 lema que está no topo da página diz 
que associação senegalesa do Rio Grande é uma instituição que serve para unir, ajudar e facilitar a necessidade dos senegaleses. A última postagem é de 2018, são fotos de preparativos para festa do Grand Magal, que se inicia com bastante antecedência, com diversas atividades. Desde então, a página, que atualmente possui 72 seguidores, não teve mais publicações. Segundo o presidente da Associação, o motivo deu-se porque o responsável pela atualização da página retornou ao Senegal, mas existe a vontade de retomar as publicações. Segundo ele, no entanto, a comunicação entre os imigrantes senegaleses que residem em Rio Grande é realizada majoritariamente via grupo de Whatsapp, com mensagens majoritariamente na língua wolof e orações em árabe, que demonstra mais uma vez o significado vinculativo entre as comunidades em diáspora, mesmo em situações temporais diferentes.

Já os integrantes da comunidade árabe-brasileira não possuem uma página própria no Facebook, mas afirmam participar de diferentes páginas de comunidades islâmicas no Brasil, a principal delas é "Mulçumanos no Brasil", com quatro mil seguidores. Os integrantes também possuem um grupo de Whatsapp, no qual as mensagens são em português e árabe.

Quando indagados sobre os diferentes tipos de rituais e práticas na mesquita, tendo em vista que os árabe-brasileiros são sunitas e os senegaleses, da vertente mouride, um dos integrantes da comunidade palestina (ENTREVISTADO 3), homem, casado, profissional liberal, de 56 anos, declarou:

A reza é a mesma, às vezes eles têm determinados cultos, de cantorias, de ler o alcorão em roda, mas a reza é mesma. Agora, eles rezam com os braços caídos ao lado do corpo e nós, os sunitas, geralmente rezamos com a mão direita sobre a mão esquerda altura do umbigo. Mas a reza é um tipo só. Ambas estão corretas. (ENTREVISTADO 3).

Já os senegaleses destacaram a importância da liberdade religiosa no Brasil, ainda que a falta de conhecimento da maioria dos brasileiros sobre os preceitos básicos do islamismo tenha sido algo constante nas falas. Sobre as possíveis dificuldades das práticas religiosas na sociedade brasileira, majoritariamente cristã, o entrevistado 4, solteiro, que trabalha na indústria pesqueira, responsável pela captura e industrialização de pescado, 31 anos, há seis anos em Rio Grande, comentou:

A gente não teve dificuldade para praticar nossa religião. Se a gente tem um evento religioso, a gente programa de uma maneira certa para ser para 
todos. Nós temos uma casa alugada específica para estes eventos religiosos além da mesquita dos árabes que frequentamos. (ENTREVISTADO 4).

É interessante refletir sobre a escolha da denominação "mesquita dos árabes", e não dos mulçumanos, nossa mesquita, ou dos brasileiros mulçumanos, mas sim os árabes, como uma comunidade transnacional. Podemos perceber assim também que o árabe é considerado uma ideia, símbolo, que se refere, ao mesmo tempo, à cultura, à sociedade e à língua. No entanto, quando indagados sobre semelhanças e diferenças, fica clara a aproximação com a cultura árabe devido à prática islâmica.

\begin{abstract}
A cultura senegalesa é bem diferente da brasileira e mais próxima da cultura árabe. 0 comportamento da gente é diferente dos dois. Na nossa cultura respeitamos os mais velhos e a relação pais e filhos. Lá é bem difícil de encontrar um filho que irá chamar um pai de mentiroso, aqui já acontece. Outra coisa é a relação mulher e homem. A última palavra é sempre do homem, como acontece com os árabes [...] Nós temos uma cultura poligâmica assim como muitos árabes, nós temos direito de casar com até quatro mulheres. Aqui nós ajudamos muito um ao outro financeiramente se alguém precisa. Esse tipo de solidariedade é da nossa cultura. Senegal é um país com uma cultura baseada no respeito. (ENTREVISTADO 1).
\end{abstract}

Deste modo, em dois diferentes domingos de 2019, ao frequentarmos uma reunião religiosa dos senegaleses, uma dahira, assim descrita no subcapítulo anterior, constatamos diferenças entre os cultos realizados na mesquita árabe sunitas e o mouridismo senegalês. Na ocasião, foram recitados khassidas, que são cantos musicais em torno de livros que ficavam no centro da sala, além da leitura do Alcorão, na língua árabe. No entanto, neste dia, cerca de quarenta senegaleses estavam presentes e o líder da Associação dos Senegaleses conversou em wolof com os presentes. Segundo ele, foram tratadas questões relativas à comunidade senegalesa, principalmente sobre os problemas relativos ao comércio de rua local e também sobre a situação de trabalho de alguns na indústria pesqueira. Atualmente, cerca de 20 senegaleses trabalham na fábrica, dois com cargos gerenciais.

Podemos constatar assim que, em situação de diáspora, o líder da associação exerce uma importante função na comunidade senegalesa em diálogo com a sociedade local, assim como acontecia com as comunidades mourides no próprio Senegal e também em outras regiões do mundo. Heil (2018), em estudo sobre senegaleses no Rio Janeiro, observou que a dahira, por sua maior estabilidade devido à devoção religiosa, se manifestou como o centro dessa infraestrutura muçulmana de chegada, fundamental para a constituição e o fortalecimento político para aquela comunidade. 
Por fim, neste ponto é válido ressaltar que, no período pesquisado, acompanhamos a luta dos senegaleses em Rio Grande, por meio da Associação, para a conquista de um espaço público que possibilite o comércio legal das mercadorias. A Prefeitura Municipal cogita disponibilizar uma área exclusiva para os senegaleses. Até o término desta pesquisa, em março de 2020, nada havia sido consolidado. Logo, torna-se difícil resistir à tentação de ler a referência à "parte dos que não fazem parte", de Ranciére (2018), pelas lentes das lutas destes imigrantes.

\section{Considerações finais}

Ao longo da pesquisa podemos constatar alguns importantes elementos comunicacionais a partir da análise do encontro entre as diferentes diásporas, principalmente em termos de colaboração, compreensão mútua, assim como desentendimentos e diferentes apropriações de usos e práticas midiáticas.

Assim como já apontado por alguns pesquisadores (LACOMBA, 2001; SAMBE, 2007; ROSSA, 2019), confirmou-se o fato de que as redes de irmandade mouride que se formam na diáspora senegalesa são de extrema importância na imigração e contribuem para a manutenção dos laços de identidade coletiva. Além disso, tais redes podem ser observadas também como espaços de construção e organização política em defesa dos direitos dos imigrantes. Assim, a partir dos relatos coletados, podemos observar também que a colaboração da comunidade árabe-brasileira na acolhida dos novos imigrantes senegaleses que chegaram nos últimos anos se mostrou importante para a fortificação da rede migratória.

Apesar das diferenças religiosas específicas, assim relatado pelos entrevistados, nos chamou a atenção que alguns integrantes da comunidade árabe-brasileira realizaram ações de acolhida aos primeiros senegaleses que chegaram à cidade, em 2013, como auxílio na busca por moradias e cestas básicas, algo que se repetiu recentemente. "São nossos irmãos mulçumanos e temos o dever de ajudá-los", comentou o entrevistado 3, quando indagado sobre esta primeira acolhida. Tal fato demonstra que o vínculo religioso, mesmo com suas diferenças peculiares, parece ser mais forte e preponderante do que as questões nacionais propriamente ditas e confirma o que Rancière (2018) sugere ao refletir sobre a relação entre religião e política e no modo como as operações do fazer das mesmas são partilhadas pelos membros dentro de uma comunidade. 
A mesquita, enquanto espaço transnacional e transcultural, para além de local meramente religioso, demonstrou ser a possibilidade para o imigrante senegalês, por meio das práticas midiáticas, efetivar relações sociais, acionar diferentes identidades e posições simultâneas em diferentes espaços. Aqui, Hall (2003) mais uma vez contribui ao afirmar que, nas situações das diásporas, "as identidades se tornam múltiplas" onde existem "elos que as ligam a uma ilha de origem específica", mas também "outras forças centrípetas" (HALL, 2003, p. 28). Ou seja, o imigrante está aqui, com os árabe-brasileiros, e lá, com o Senegal, algo que, em última instância, auxilia no efetivo enfrentamento das vicissitudes da imigração e das dificuldades do lugar de sua vivência e atuação.

Ainda, nesse sentido, a relação entre religião e migração em contexto de diáspora mostrou-se como o prolongamento de vínculos, circulação, interação, mais do que a perda, marcada pela partida. Em outras palavras, os espaços de prática religiosa transpõem os aspectos espirituais, servindo, também, como um ambiente de proteção.

Torna-se evidente que as práticas islâmicas na costa ocidental africana sejam mais voltadas para questões místicas. Logo, além de romper com os estereótipos representacionais, os senegaleses muçulmanos também se diferenciam ritualisticamente das comunidades árabes tradicionais. No entanto, acreditamos que compreender as particularidades da vida destes imigrantes, no cenário de diáspora, em especial, sobre aspectos religiosos, serve para contribuir na desmistificação de algumas opiniões preconceituosas, de entendimentos generalistas, difusão de informações sobre as práticas muçulmanas no Brasil, até mesmo dentro da própria comunidade árabe-brasileira.

Por fim, compartilhamos nossa empreitada científica comunicacional com a proposta de Sodré ao perceber que "as diferenças se determinam mutuamente no processo e no encontro" (SODRÉ, 2017, p. 22), algo presente na comunicação transcultural entre as diferentes diásporas, que, mesmo temporalmente e geograficamente distantes, conseguem dialogar e contribuir para o enriquecimento de ambas. Gaza e Dakar encontram-se todas as sextas-feiras ao sul do Brasil. As interações comunicacionais demonstraram-se possíveis mesmo que não verbalmente, mas na prática e na luta cotidiana de ambas as comunidades. 


\section{Referências bibliográficas}

ASSOCIAÇÃO DOS SENEGALESES DE PORTO ALEGRE. 2018. Facebook: adspoa. Disponível em: https://www.facebook.com/adspoa/. Acesso em: 22 out. 2019.

ASSOCIAÇÃO DOS SENEGALESES DO RIO GRANDE. 2017. Facebook: nagnu.ande.liguey. Disponível em: https://www.facebook.com/nagnou.ande.liguey/ Acesso em: 13 out. 2019.

BRIGNOL, Liliane Dutra; COSTA, Nathália. Diáspora senegalesa e mediação tecnológica: entre tempos e lugares na observação do Magal de Touba. Contracampo, Niterói, v. 37, n. 1, 2018.

CAVALCANTI, Leonardo; OLIVEIRA, Antônio Tadeu; MACÊDO, Marília Fernandes Rodrigues de; PEREDA, Lorena del Pilar. Resumo Executivo. Imigração e Refúgio no Brasil. A inserção do imigrante, solicitante de refúgio e refugiado no mercado de trabalho formal. Observatório das Migrações Internacionais; Ministério da Justiça e Segurança Pública / Conselho Nacional de Imigração e Coordenação Geral de Imigração Laboral. Brasília, DF: OBMigra, 2019.

DIAS, Eduardo Costa. Senegal: confrarias, contrato social e modernidade. Janus, OBSERVARE - Observatório de Relações Exteriores da Universidade Autónoma de Lisboa, Lisboa, Portugal, 2007.

ECOVIX demite 32 mil trabalhadores do Polo Naval de Rio Grande. 2016. Disponível em: http://www.riogrande.rs.gov.br/opolonaval/index.php/noticias/detalhes+29b,,ecovixdemite-32-mil-trabalhadores-do-polo-naval-de-rio-grande-html. Acesso em: 22 nov. 2019.

ELHAJJI, Mohammed; ESCUDERO, Camila. Webdiáspora: Migrações, TICs e memória coletiva. In: SODRÉ, Muniz et al. (org.). Diásporas urbanas: migrantes, viajantes e transeuntes. Goiania: Gráfica UFG, 2015, p. 19-41.

ELHAJJI, Mohammed. Rio de Janeiro - Montreal: Conexões transnacionais / Ruídos interculturais. In COGO, Denise; ELHAJJI, Mohammed; HUERTAS, Amparo (eds.): Diásporas, migrações, tecnologias da comunicação e identidades transnacionais, Bellaterra: Universitat Autònoma de Barcelona, 2012, p. 31-42.

GILROY, Paul. O Atlântico Negro: modernidade e dupla consciência. São Paulo: Ed. 34, 2001.

HALL, Stuart. Da diáspora: identidades e mediações culturais. Organização Liv Sovik. Belo Horizonte: Editora UFMG; Representação da UNESCO no Brasil, 2003.

HALL, Stuart. Cultura e representação. Rio de Janeiro: Ed. PUC-Rio: Apicuri, 2016.

HEIL, Tilmann. Uma infraestrutura muçulmana de chegada no Rio de Janeiro. REMHU, Revista Interdisciplinar de Mobilidade Humana, Brasília, v. 26, n. 52, 2018, p. 111-129.

JUNG, Philipp Roman. Desenvolvimento de processos migratórios do Senegal para o Brasil e suas alterações. In: TEDESCO, João Carlos (org.). Imigração senegalesa: múltiplas dimensões. v. 2. Porto Alegre: EST Edições, 2019, p. 45-76. 
LACOMBA, Joan. Inmigrantes senegaleses, Islam y cofradías. Revista Internacional de Sociología, Córdoba, n. 29, maio/ago. 2001.

MARTINO, Luís Mauro Sá. Mídia, Religião e Sociedade: das palavras às redes digitais. São Paulo: Paulus, 2016.

MONTENEGRO, Silvia. As Comunidades Muçulmanas na Tríplice Fronteira: Identidades Religiosas, Contextos Locais e Fluxos Transnacionais. In: Reunião Brasileira De Antropologia, 26a, 2008, Porto Seguro. Anais [...], Porto Seguro, 2008.

ORGANIZAÇÃO INTERNACIONAL PARA MIGRAÇÕES, World Migration Report 2020. Disponível em: https://publications.iom.int/books/world-migration-report-2020. Acesso em: dez. 2020.

PINTO, Paulo Gabriel Hilu da Rocha. Árabes no Rio de Janeiro: uma identidade plural. Rio de Janeiro: Cidade Viva, Instituto Cultural Cidade Viva, 2010.

RANCIÈRE, Jaques. 0 Desentendimento: política e filosofia. São Paulo: Editora 34, 2018.

ROSSA, Juliana. Seguidores de Cheikh Ahmadou Bamba: apontamentos etnográficos sobre a vivência da fé no contexto migratório de senegaleses Mourides. In: TEDESCO, João Carlos (org.). Imigração senegalesa: múltiplas dimensões, v. 2. Porto Alegre: EST Edições, 2019, p.287-312.

ROBERTO, Simone Assis Alves; PINHEIRO, Patrícia dos Santos. Do Senegal a Pelotas, RS: Migração, Identidade e Violência. Século XXI. Revista de Ciências Sociais, Fortaleza, v. 9, n. 1, p. 123-158, jan./jun. 2019

SAMBE, Bakary. Senegal: un islam local em épocas de globalización religiosa. Janus Anuário, OBSERVARE - Observatório de Relações Exteriores da Universidade Autónoma de Lisboa, Lisboa, Portugal. 2007.

SAYAD, Abdelmalek. Imigração ou os Paradoxos da Alteridade. São Paulo: EDUSP, 1998.

SECRETARIA NACIONAL DE JUSTIÇA. Refúgio em Números. 3ª. ed. Brasília, 2018. Disponível em:https://www.justica.gov.br/seus-direitos/refugio/anexos/refasgio-em nasmeros_1104.pdf. Acesso em: 22 out. 2020.

SODRÉ, Muniz. Pensar Nagô. Rio de Janeiro. Vozes, 2017.

SODRÉ, Muniz. Ciência do Comum. Rio de Janeiro: Vozes, 2014.

SODRÉ, Muniz. As estratégias sensíveis. Afeto, Mídia e Política. Petrópolis: Vozes, 2006.

TEDESCO, João Carlos. Apresentação. In: TEDESCO, João Carl (org.) Imigração senegalesa: múltiplas dimensões. v. 2. Porto Alegre: EST Edições, 2019, p. 9-20. 


\title{
New and old Diasporas: a cross-cultural communication between Senegalese and Arab-Brazilians in southern Brazil.
}

\begin{abstract}
The article brings reflections from a communicational study on socio-cultural relations between the recent Senegalese immigration in the southern region of Rio Grande do Sul, started in the second decade of 2000, and the Arab-Brazilians living in Brazil since the beginning of the last century. The theoretical basis for this study is mainly on the assumptions of Muniz Sodré, Stuart Hall and Jacques Rancière. A field research was carried out with participant observation and semi-structured interviews with representatives of both communities. We observed that the communicational interactions proved to be possible and active between the communities, with aspects of collaboration, understanding, as well as disagreements and different appropriations of media uses and practices.
\end{abstract}

\section{Keywords}

Migrations. Contemporary Culture. Religion. New technologies. Diaspora.

\section{Autoria para correspondência}

Guilherme Oliveira Curi

Curi.guilherme@gail.com

\section{Como citar}

CURI, Guilherme Oliveira; BRIGNOL, Liliane Dutra. Novas e antigas diásporas: a comunicação transcultural entre senegaleses e árabe-brasileiros no sul do Brasil. Intexto, Porto Alegre, n. 52, e-104760, jan./dez. 2021. DOI: http://dx.doi.org/10.19132/1807-8583202152.104760

Recebido em 25/06/2020

Aceito em 22/02/2021 